This item was submitted to Loughborough's Research Repository by the author.

Items in Figshare are protected by copyright, with all rights reserved, unless otherwise indicated.

\title{
Microfiltration enhancement by electrical and ultrasonic force fields
}

PLEASE CITE THE PUBLISHED VERSION

PUBLISHER

(C) Elsevier

VERSION

AM (Accepted Manuscript)

LICENCE

CC BY-NC-ND 4.0

REPOSITORY RECORD

Tarleton, E.S., and Richard J. Wakeman. 2009. "Microfiltration Enhancement by Electrical and Ultrasonic Force Fields". figshare. https://hdl.handle.net/2134/5358. 
This item was submitted to Loughborough's Institutional Repository (https://dspace.lboro.ac.uk/) by the author and is made available under the following Creative Commons Licence conditions.

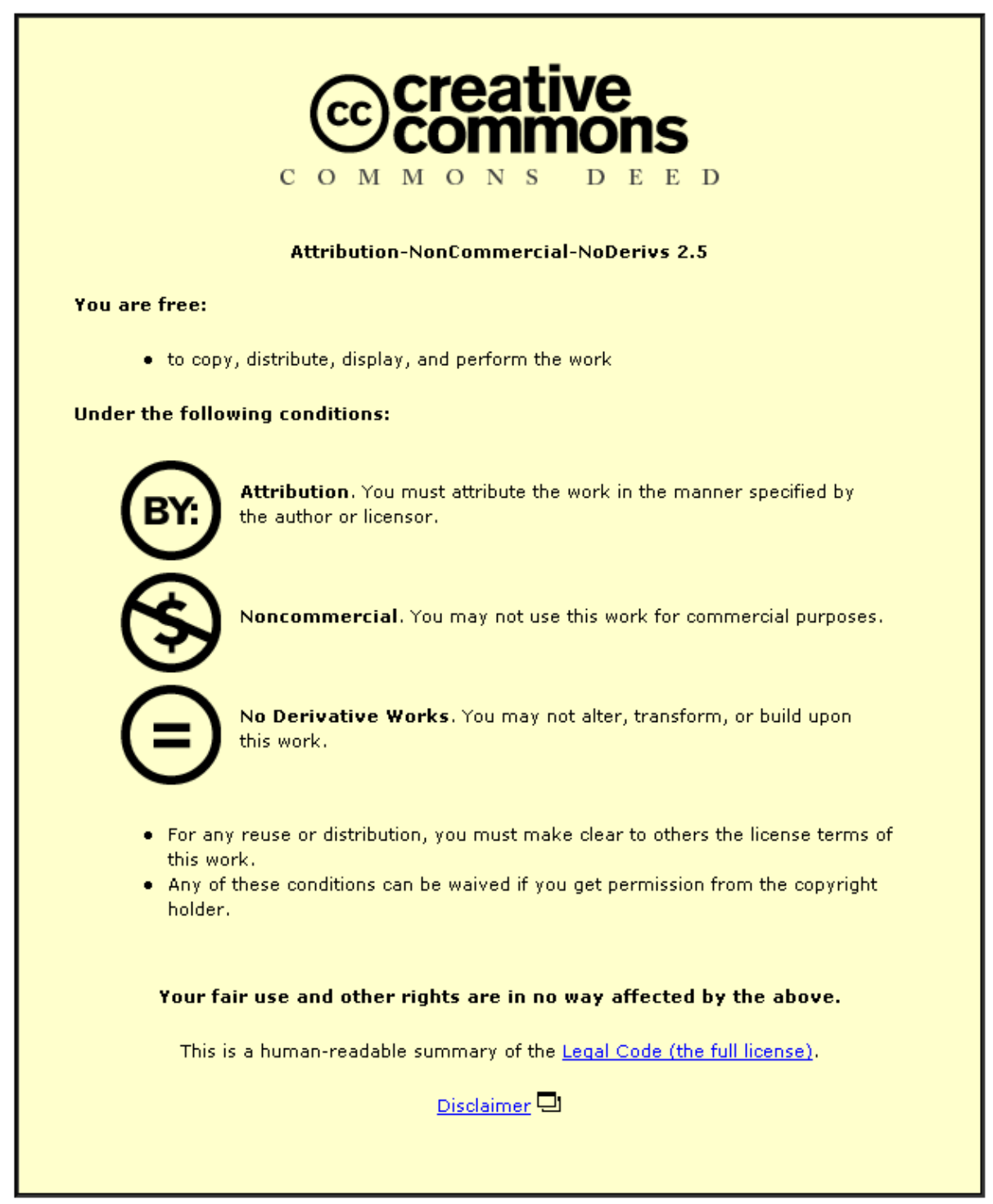

For the full text of this licence, please go to: http://creativecommons.org/licenses/by-nc-nd/2.5/ 


\title{
MICROFILTRATION ENHANCEMENT BY ELECTRICAL AND ULTRASONIC FORCE FIELDS
}

\author{
E.S. Tarleton (e.s.tarleton@lboro.ac.uk) and R.J. Wakeman \\ Separation Processes Centre, University of Exeter, North Park Road, Exeter, Devon, EX4 4QF, \\ UK.
}

\begin{abstract}
'Assisted' filtration techniques are emerging as technical alternatives to conventional separations. Experimental data presented in this paper show how electric and ultrasonic fields can assist microfiltration by reducing the flux decline caused by membrane fouling. Effects of the fields acting individually and in combination are illustrated, together with the influence of other filtration parameters.
\end{abstract}

\section{INTRODUCTION}

Membrane technology has revolutionised the separation of fine particle suspensions. The emergence of ultra- and micro- filtration has allowed many types of colloidal dispersions, carrying particles and solutes finer than $10 \mu \mathrm{m}$, to be separated and processed more effectively. Whilst membrane separations are used extensively in many industries (see Table 1) the phenomenon of membrane fouling remains a recurring problem in many areas ${ }^{1-4}$. The accumulation of macromolecular and finer particulate material at the septum during filtration can initiate rapid flux decline and result in unacceptably low separation rates. The complexity of the interactions between membranes and process streams have only allowed a limited understanding of the mechanisms of fouling, and methods of prevention are likewise restricted ${ }^{5,6}$. Recently, however, improvements in technology have enabled 'assisted filtrations' to emerge as potentially viable alternative techniques for reducing fouling. These utilise suitable electrical, sonic or magnetic force fields to modify the performance of an otherwise conventional membrane separation and provide for improved efficiency.

This paper describes how improved electric and ultrasonic fields can influence the microfiltration of colloidal and near colloidal sized aqueous suspensions. Data are presented which illustrate the effects of both individual and combined fields as well as the influence of parameters such as crossflow velocity and suspension concentration.

\section{EXPERIMENTAL APPARATUS}

The experimental equipment used in the filtration tests is shown schematically in Figure 1. A suspension made up to a known solids concentration and $\mathrm{pH}$ in twice distilled water, was pumped into a pressure leaf filter which had been modified by the addition of planar stainless steel electrodes located either side of the membrane and ultrasound transducers on the feed side of the membrane. Depending on the configuration used it was possible to vary the experimental conditions over the range:

Electric field: $0 \rightarrow 400 \mathrm{~V} \mathrm{DC}, 10 \mathrm{~A}$ max.

Electrode separation: $3 \rightarrow 6 \mathrm{~cm}$

Membrane area: $240 \rightarrow 38 \mathrm{~cm}^{2}$

Ultrasonic field: 23 or $40 \mathrm{kHz}, 600 \mathrm{~W}$ max.

Distance between acoustic source and membrane: $15 \rightarrow 110 \mathrm{~mm}$

Crossflow velocity of the process stream: $0 \rightarrow 0.2 \mathrm{~m} \mathrm{~s}^{-1}$ 
The crossflow velocities used in this work were lower than those used in the usual mode of crossflow microfiltration, since less shear is required at the membrane surface when an assisting force is used during the filtration.

Filtrations were performed at constant pressure for periods of up to two hours with the cumulative permeate volume being monitored throughout. In conjunction with these experiments several subsidiary tests were done to characterise and identify potentially suitable suspensions. The results of these tests for the solid types used are summarised in Table 2.

\section{EXPERIMENTAL RESULTS AND DISCUSSION}

The following data illustrate some of the trends which were observed in the electroacoustic filtrations.

Figure 2 shows a typical result when an acoustic field was applied simultaneously with a low crossflow velocity. With no acoustic field present the permeate flux was found to fall sharply during the initial stages of filtration. Subsequently the flux continued to decline gradually to a fairly low equilibrium level. When an acoustic field was imposed from the start of filtration, appreciable increases in flux were achieved. In the particular example shown a 6-10 fold increase in the equilibrium flux was seen with the ultrasound source $32 \mathrm{~mm}$ from the septum surface. These effects can currently only be partially explained. The motion of a sound wave through a suspension is described by the wave equation ${ }^{7}$ with the depth of penetration $(x)$ being related to the source intensity $\left(u_{0}\right)$ by

$$
u_{x}=u_{0} \exp (-\alpha x)
$$

where $a$ is the intensity attenuation coefficient $\left(\mathrm{m}^{-1}\right), u_{x}$ the ultrasound intensity at a distance $x$ from the sound source $\left(\mathrm{W} \mathrm{m}^{-1}\right)$.

Thus, further improvements in permeate flux would be expected by decreasing the sourcemembrane distance. The effect was found experimentally, and an example of how increased ultrasound intensity at the septum surface improves filtration is shown in Figure 2. However, the mechanisms by which the flux improvement occurred are more difficult to explain. It is claimed that the passage of sound waves through a two-phase suspension can generate high inertial forces at the solid-liquid interfaces ${ }^{8}$. If these are of sufficient magnitude then particle motion relative to the fluid may result. The experimental results appear to suggest that such a process occurs at or near the membrane surface. This in turn allows the crossflowing process stream to re-entrain some of the particulate matter responsible for fouling and facilitate an improved flux. Whilst such a mechanism may occur, it has also been reported that many other factors such as particle size, shape, surface charge, and solution environment can alter the fouling rate ${ }^{9}$. By whatever mechanisms acoustics assist membrane filtration, the effects are often substantial and may be achieved with a range of solid types. Some further example data for the filtration of china clay are shown on Figure 3.

The data in Figure 4 show the typical effect of applying an electric field during microfiltration. The mechanisms acting here are relatively well understood (see $\left.{ }^{10-14}\right)$. Most particulate substances acquire a surface charge when in aqueous suspension, which may be measured in terms of zeta potential ( $\zeta$ ). It was previously found that, using a pleated membrane in crossflow filter, $|\zeta|>20$ $\mathrm{mV}$ and particle diameter is $<6 \mu \mathrm{m}$ induces both electrophoresis and electroosmosis to enable flux improvements during filtration. What is of interest here, however, is the manner by which an electric field can not only help prevent particulate deposition but also assist in the removal of previous deposits from a separating surface. The result of such a process is seen in Figure 5 where, after a short fouling period, particles are lifted from the membrane and re-entrained into the 
crossflowing stream by the action of the electric field. The results also implied, and previous studies have supported the theory ${ }^{10,16}$, that with a sufficiently high electric field strength little or no membrane fouling by particulate matter occurs and separation proceeds at close to a maximum rate. While this situation may not always be achieved in practice, filtrations at high flux levels are readily demonstrated.

More recently there has been a growing realisation that combined field separations may provide techniques whereby membrane fouling can be further alleviated ${ }^{15}$. Figure 5 shows data obtained for the filtration of a $1.7 \% \mathrm{v} / \mathrm{v}$ china clay suspension. Both individual electric and ultrasonic fields were seen to reduce fouling and improve the permeate flux levels. However, when the two fields were applied simultaneously the flux performance recorded was better than the additive effects of the individual fields. There currently exists a degree of uncertainty about the coupling mechanisms which could account for this synergistic effect. One theory supposes that the passage of the sound waves through the suspension provides for better electrical continuity to induce improved electroosmotic flow. It is difficult to perceive how this might be so unless the acoustics are facilitating better ion transport through the solution. Others postulate that changes at the microscopic level promote more favourable conditions for electrofiltration.

The data further suggest that another process may contribute significantly to the synergism observed. Figure 6 shows how this may occur. With no imposed force fields, fouling of the membrane results by an accumulation of particulate matter at the separating surface ('a'). The deposited colloidal material is sufficiently well 'trapped' at the entrances to the pores of the membrane to prevent re-entrainment by the crossflowing stream. In the presence of an electric field particulates are caused to move away from the membrane and facilitate improved flux ('b'). However, where the imposed electrical potential is below the threshold required to eliminate deposition, some particles can still be expected to foul the membrane. By applying ultrasonic and electric fields simultaneously many of these remaining particles can be removed. The passage of ultrasound waves through a fluid or suspension can induce cavitation, which is observed as the rapid formation and collapse of gaseous microbubbles ${ }^{17}$. It is postulated that at the pore entry regions nucleation of the bubbles occurs, and that upon bubble collapse the convective action induced at the membrane surface causes trapped particulates to be loosened. The small motion of the particle moves it out of the pore entry region into a zone of favourable electric field gradient which carries it further into the crossflowing stream ('c' and ' $d$ '). The crossflow stream is then able to carry the particle away from the filtering surface.

\section{CONCLUSIONS}

Membranes and membrane related separations are likely to become an increasingly important feature of solid-liquid separation. Of equal importance, however, will be the need to control fouling. The work presented in this paper shows how assisted filtration techniques can promote fouling prevention and facilitate improved separation rates. Both individual and combined electric and acoustic fields can reduce membrane fouling caused by the deposition of colloidal material over a range of operating conditions. The rate of fouling is affected by parameters such as field strength, suspension concentration, crossflow velocity, particle size, shape and surface characteristics. The ability to prevent fouling to a significant extent using these techniques and suitably engineered equipment will enable electric, acoustic and electroacoustic filtrations to become an increasingly viable proposition. This technology may provide the engineer with a wider range of separation techniques.

\section{ACKNOWLEDGEMENT}


The authors wish to record their gratitude to the Science and Engineering Research Council for supporting this work. The project was funded under the auspices of the Specially Promoted Programme in Particulate Technology.

\section{REFERENCES}

1. Milisic V. and Ben Aim B., Filtr. and Separ., 23(1), 28 (1986).

2. Gutman R.G., Membrane Filtration: The Technology of Pressure-Driven Crossflow Processes, JOP, England (1987).

3. Murkes J. and Carlsson C.G., Crossflow Filtration, Wiley (1988).

4. Fane A.G., in Progress in Filtration and Separation, Vol. 4, R.J. Wakeman (Ed.), Elsevier, Amsterdam (1986).

5. Bertera R.G., Metcalfe M.G. and Steven J.H., Chem. Engr., June 10, (1984).

6. Kristensen S., Proc. $4^{\text {th }}$ World Filtration Congress, Ostend, Belgium, 22-25 April 1986.

7. Bhatia A.B., Ultrasonic Absorption: An Introduction to the Theory of Sound Absorption and Dispersion in Gases, Liquids and Solids, Dover, New York (1985).

8. Advances in Solid-Liquid Separation, H.S. Muralidhara (Ed.), Batelle, Ohio (1986).

9. Tarleton E.S., Filtr. and Separ., 25(6), 402 (1988).

10. Tarleton E.S., Ph.D. Thesis, University of Exeter (1986).

11. Yukawa H., Kobayashi K., Yoshida H. and Iwata M., in Progress in Filtration and Separation, Vol. 1, R.J. Wakeman (Ed.), Elsevier, Amsterdam (1979).

12. Wakeman R.J. and Tarleton E.S., Filtr. and Separ., 23, 174 (1986).

13. Wakeman R.J. and Tarleton E.S., Chem. Eng. Sci., 42, 829 (1986).

14. Tarleton E.S. and Wakeman R.J., J. Drying Technol., 6, 547 (1988).

15. J. Drying Technol., 6(3), 361-570 (1988).

16. Moulik S.P., Env. Sci. Technol., 5, 771 (1971).

17. Suslick K.S., Scientific American, Feb., 62 (1989). 


\section{TABLES AND FIGURES}

\begin{tabular}{|l|l|}
\hline Industry & Example of application \\
\hline Water treatment & Purification of brackish and seawater \\
Pharmaceuticals & Clarification of fermentation products, e.g. antibiotics and vaccines \\
Biotechnology & Cell concentration \\
Food processing & Production of sauces and curds \\
Beverage production & Production of potable liquids, e.g. beer \\
Oil industry & Secondary oil recovery \\
Electronics & Production of ultrapure water for the manufacture of semiconductors \\
Nuclear industry & Removal of waste material from uranium mining \\
\hline
\end{tabular}

Table 1: Some applications of membrane separation.

\begin{tabular}{|l|l|l|}
\hline Suspension property & Anatase & China clay \\
\hline Particle size $(\mu \mathrm{m})$ & 0.2 & 2 \\
Particle shape & Ellipsoidal (prolate) & Platelet \\
Zeta potential $(\mathrm{mV})$ & $\mathrm{pH} \mathrm{6.6,} \mathrm{zeta}=-40 \mathrm{mV}$ & $\mathrm{pH} 6.2$, zeta $=-30 \mathrm{mV}$ \\
Isoelectric point & $\mathrm{pH} \mathrm{5.8}$ & $\mathrm{pH} 3.0$ \\
\hline
\end{tabular}

Table 2: Measured properties of the test suspensions. 


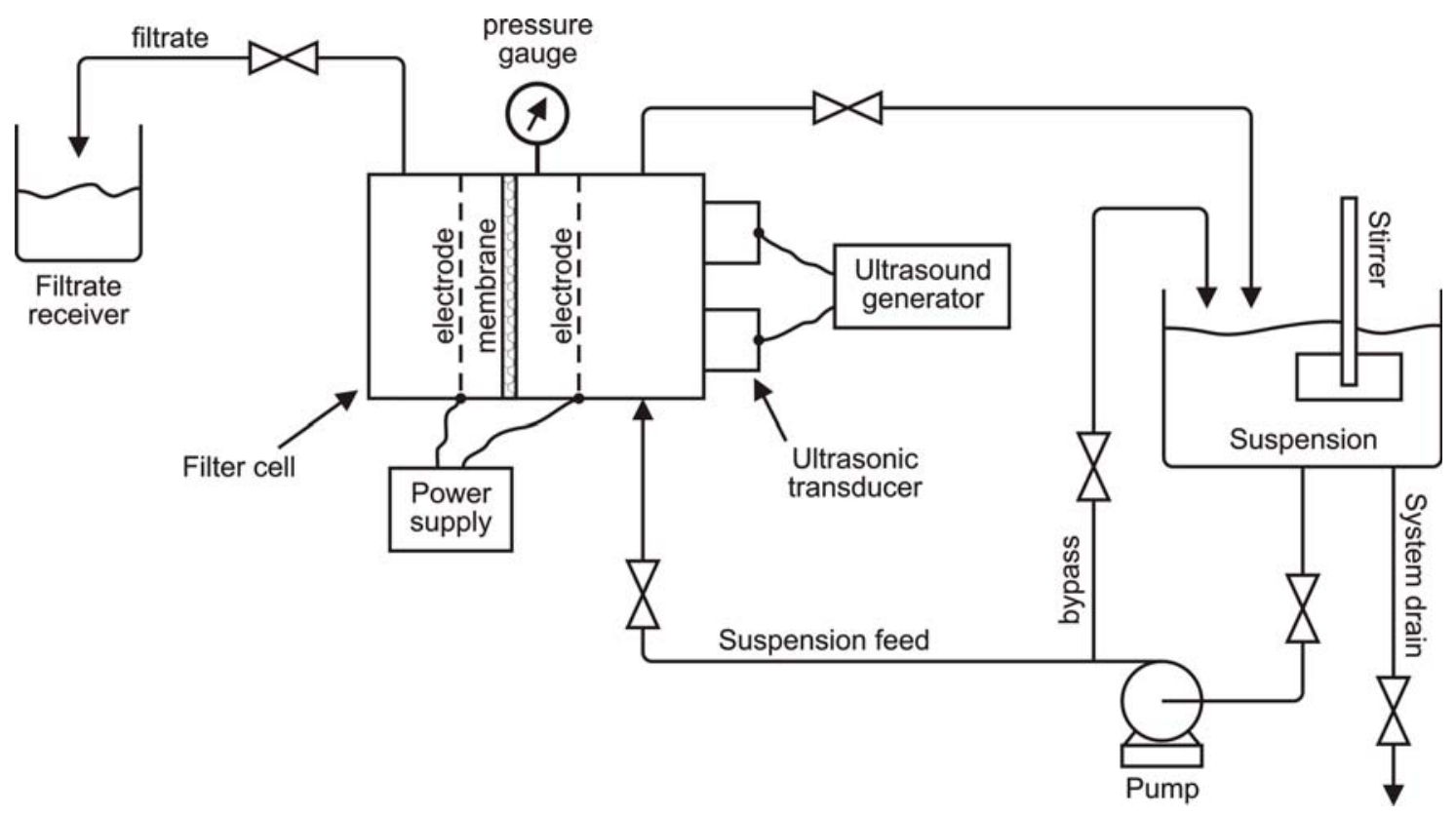

Figure 1: Schematic diagram of electroacoustic filter.
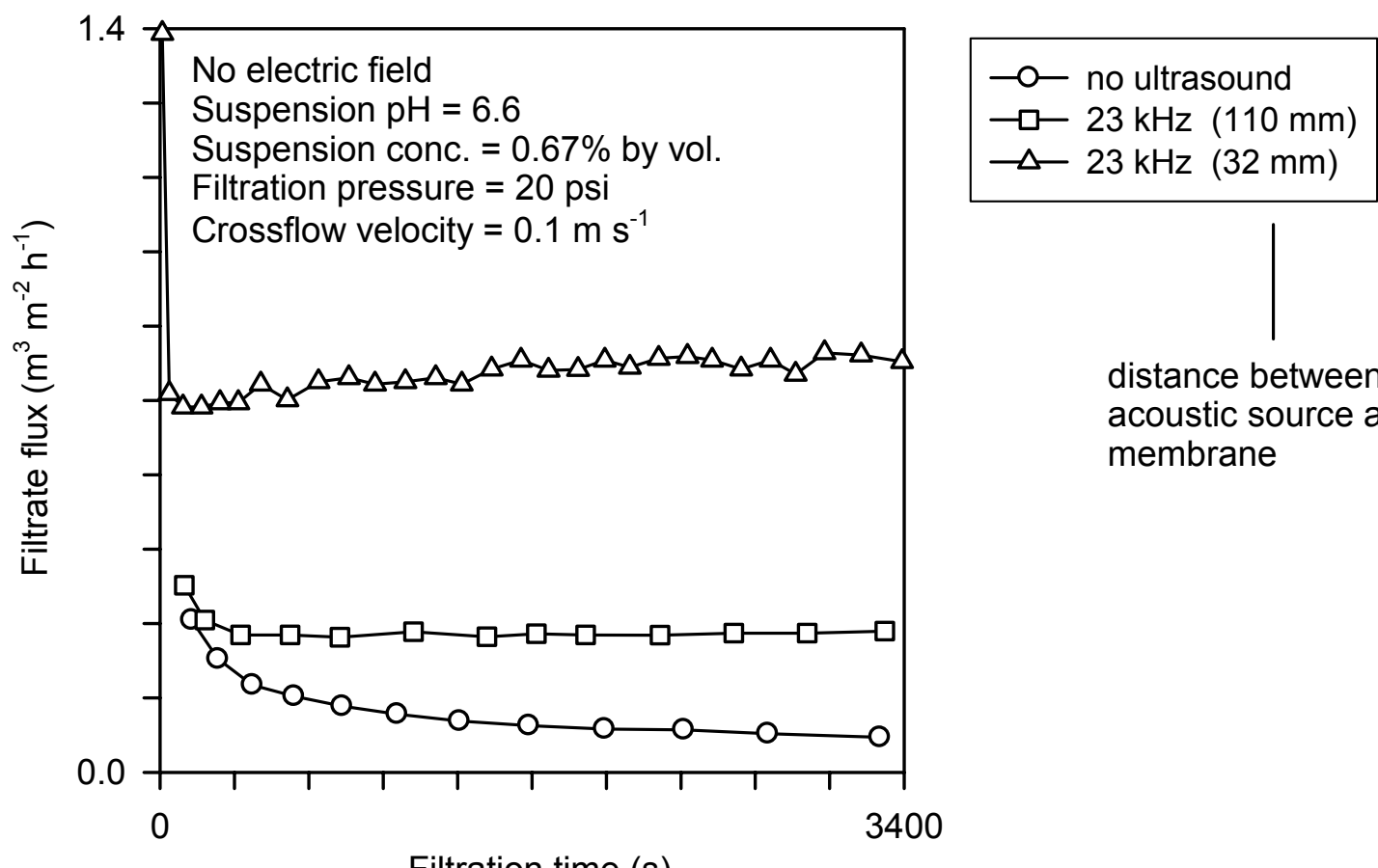

distance between acoustic source and membrane

Filtration time (s)

Figure 2: Effect of membrane/ultrasonic source separation distance on the acoustic filtration of an anatase suspension. 


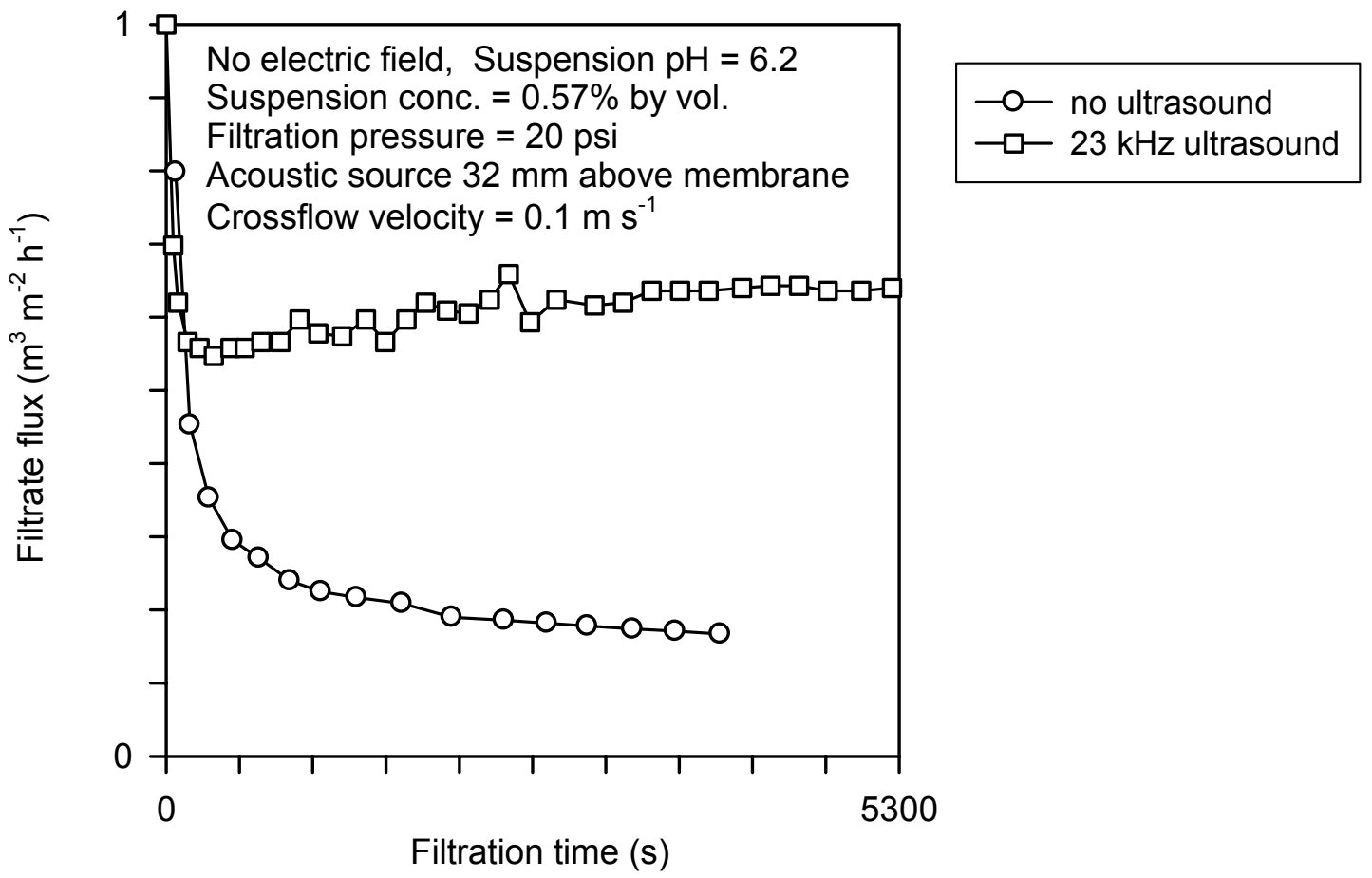

Figure 3: Effect of ultrasound on the filtration of a china clay suspension.

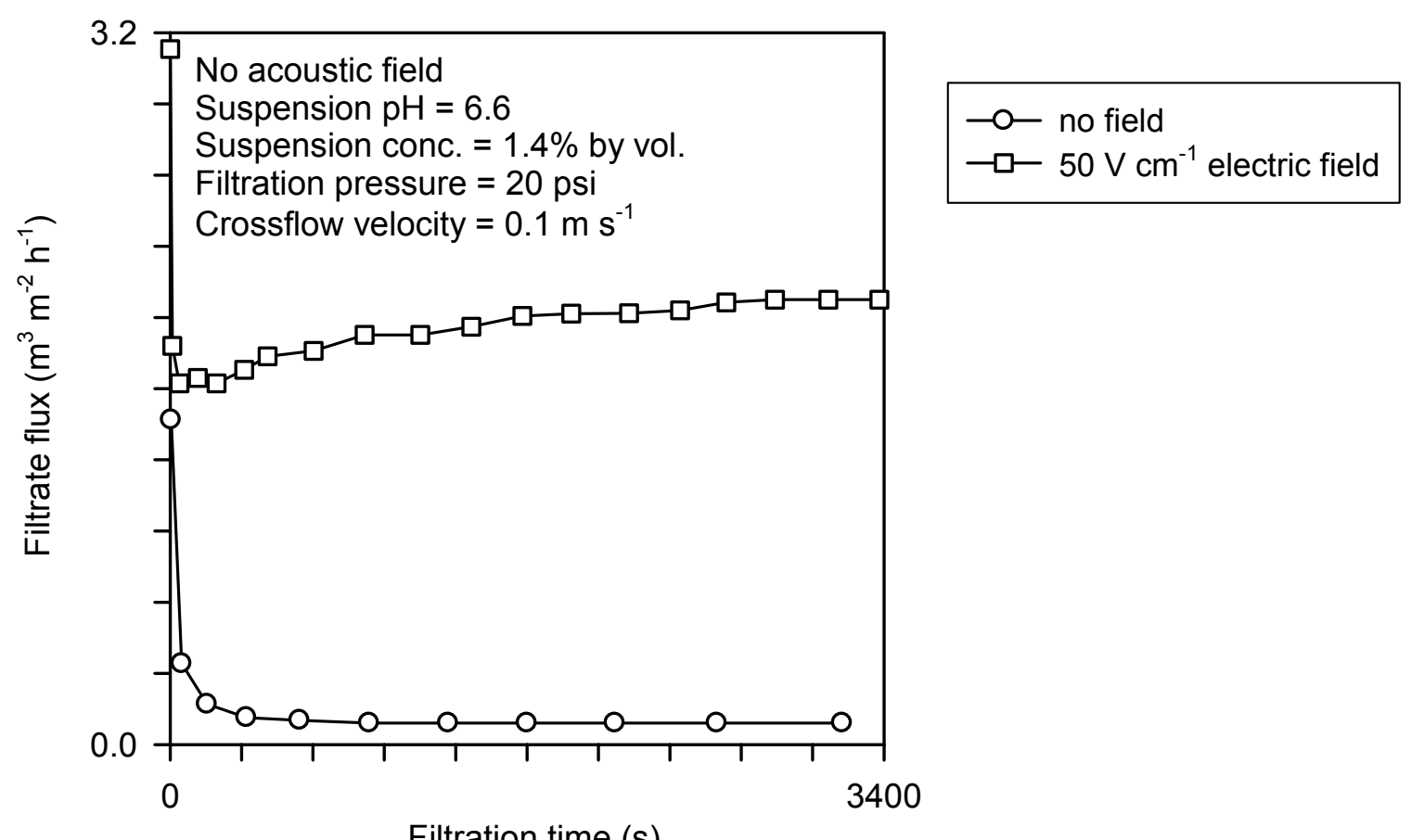

Figure 4: Effect of an electric field on the filtration of an anatase suspension. 


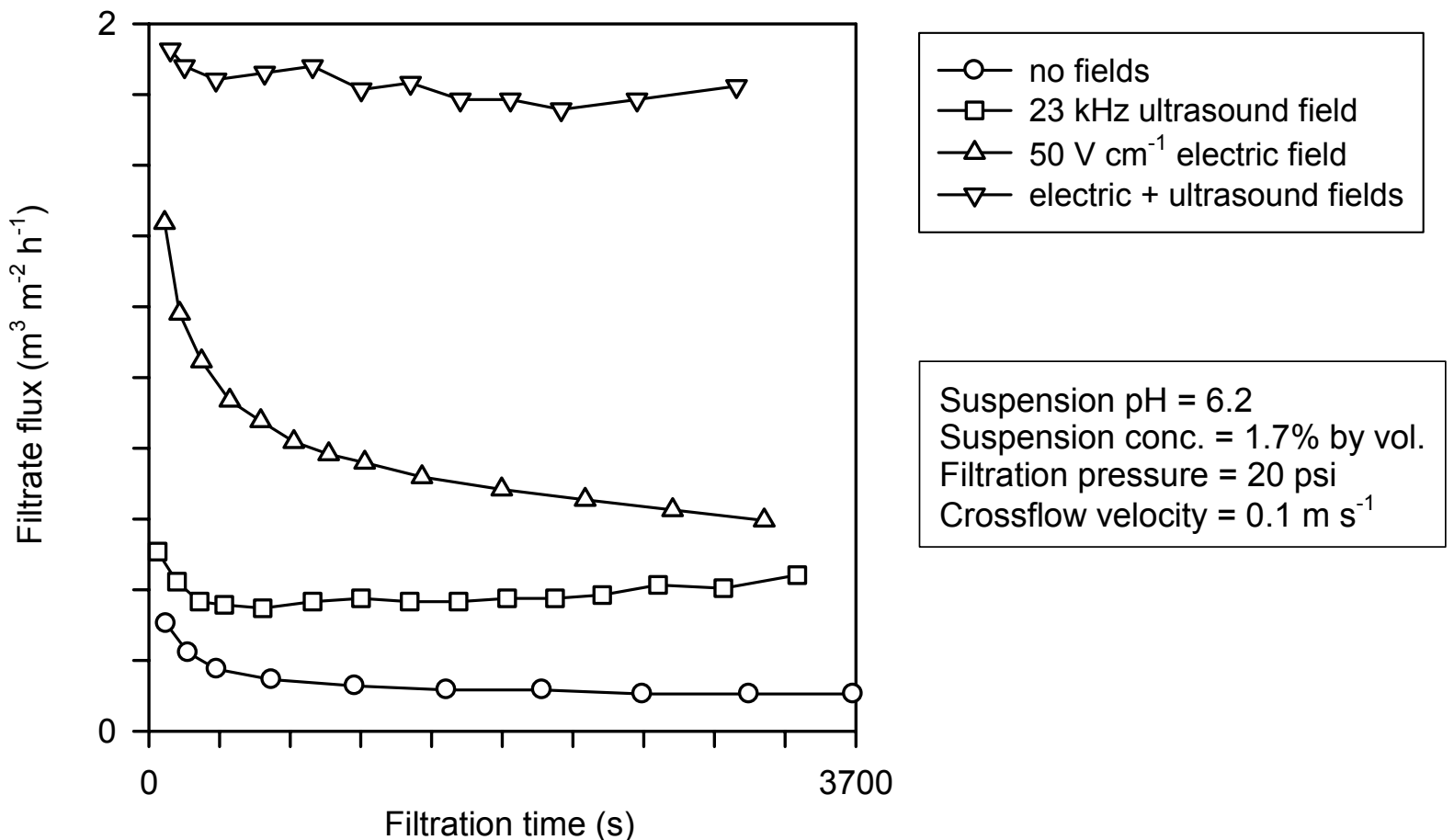

Figure 5: Effect of electric and ultrasound field on the filtration of a china clay suspension.

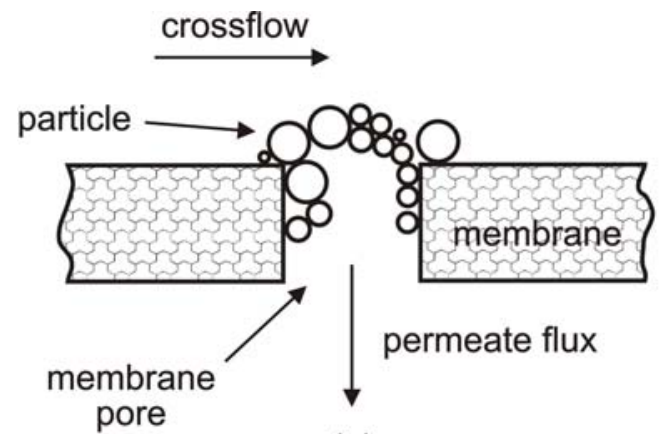

(a)

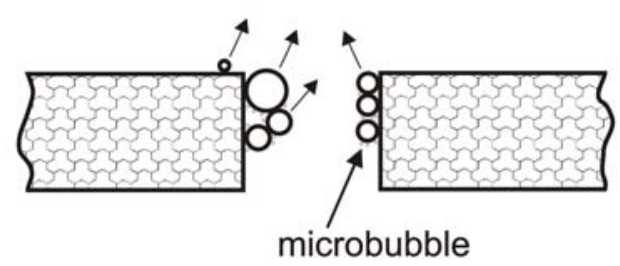

(c)

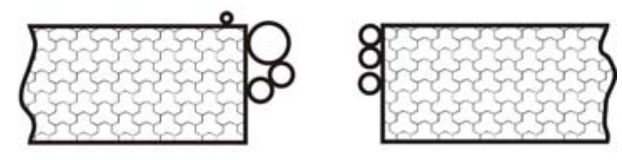

(b)
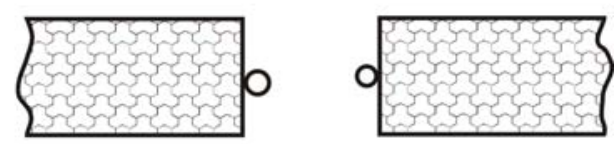

(d)

Figure 6: Possible mechanism for the synergistic coupling of electric and ultrasound force fields. 